\title{
Numerical and Experimental Study on Indoor Air Distribution and Quality
}

\author{
Zhen $\mathrm{GaO}^{1,3}$, Yun Jiang ${ }^{2,3}$, Kuangzhong Ouyang ${ }^{2,3}$, Haowei $\mathrm{Hu}^{2,3,{ }^{*}}$, Siwei \\ Zhang ${ }^{1,3}$, Jinwei $\mathrm{Ma}^{2,3}$ \\ ${ }^{1}$ Chinese Hefei Railway Constrction Real Estate Group C.O.. Ltd, Hefei 230041, China \\ ${ }^{2}$ College of Environment and Energy Engineering, Anhui Jianzhu University, Hefei 230601, China \\ ${ }^{3}$ Anhui Advanced Technology Research Institute of Green Building, Anhui Jianzhu University, Hefei \\ 230601, China \\ *Email: huhaoweihhw@foxmail.com
}

\begin{abstract}
Keywords: fresh air system; air distribution; optimization study; simulation
Abstract. To optimize and control the indoor air distribution and quality, theindoor temperature and humidity were measured based on indoor fresh air system. The one measurementwas indoor temperature and humidity in both cases of return air and without return air in winter respectively. The other was indoor temperature and humidity in both cases of return air and without return air in summer respectively. In additional,the test room environment was simulated using the finite element analysis software of ANSYS.Through setting a variety of air organization operating modes, the best solution of indoor air flow could be obtained.
\end{abstract}

\section{Introduction}

China has experienced rapid economic growth and urbanization in the past three decades ${ }^{[1]}$. Along with this process, a large number of buildings have been built. Improvement of indoor air quality and protection of human health are important goals for contemporary architectural environments ${ }^{[2]}$. Indoor air distribution and quality is important for architectural environments. It has been reported that the over-standard rate of formaldehyde and TVOC in underground buildings has reached $66.7 \%$ and $77.8 \%$ respectively in $\mathrm{Xi}^{\prime}{ }^{[3]}$. Emissions of formaldehyde and TVOC are influenced by many environment factors ${ }^{[4-6]}$, such as temperature, humidity, air velocity and merchandise materials.

To investigate the optimal control method of indoor air distribution and quality, indoor fresh air quantity is first obtained, and it is a key factor for indoor air quality. Fresh air can help wipe off indoor pollutants, which is diluted to the allowed range. The investigation on indoor air quality plays significant role in the field of controlling indoor air pollution. To control the indoor thermal environment effectively, furthermore, the return fan is being added to acquire the formation of organized exhaust. However, there are less quantitative researches on the effects of fresh air on the improvement of the thermal environment so far.

\section{Measurement methods}

The reception room on the third floor was selected for the test room. Testing equipment was installed. The acquired and heat pump data were collected in the data collection system. Based on the computational fluid dynamics (CFD) software of ANSYS, the numerical model of the indoor environment was established. After the model validation, ventilation scheme are optimized by the different working conditions.

Test scheme The methods of indoor and outdoor temperature and humidity test are described as followed. Two blowers were equipped in the system. And they were connected with two supplied outlets of fresh air respectively, as shown in Fig. 1. The rated volume flow of fresh air was $135 \mathrm{~m}^{3} / \mathrm{h}$, and the volume flow could be adjusted. The measurement contents of fresh air system were indoor temperature and humidity conditions in winter and summer with and without return air. During the debugging period, six sets of indoor temperature and humidity measuring instrument were placed in three different place, two of the same plane position instrument settings in different heights, be away 
from the floor one meter and two meters respectively. According to the requirement of external temperature conditions, the operation was carried out in the coldest and hottest month. Therefore, in our work, the winter and summer were selected, and each phase test kept for two weeks. Two stages arranged before and after the New Year's Day in 2015 and before and after July in 2015 respectively. Apparatus in different places included six sets of indoor temperature and humidity testing instrument, two of the same plane position instrument settings in different heights. The distances between the apparatus and floor were $1 \mathrm{~m}$ and $2 \mathrm{~m}$, respectively. And an outdoor temperature and humidity meter was decorated on the outdoors wall of the testing room. Two weeks of each phase testing time specific arrangement was as followed. The one was that testing indoor and outdoor temperature and humidity conditions in the case of indoor fan back closure in the measurement of the first week. The other was the testing indoor and outdoor temperature and humidity in the case of open the indoor fan back in the first week.

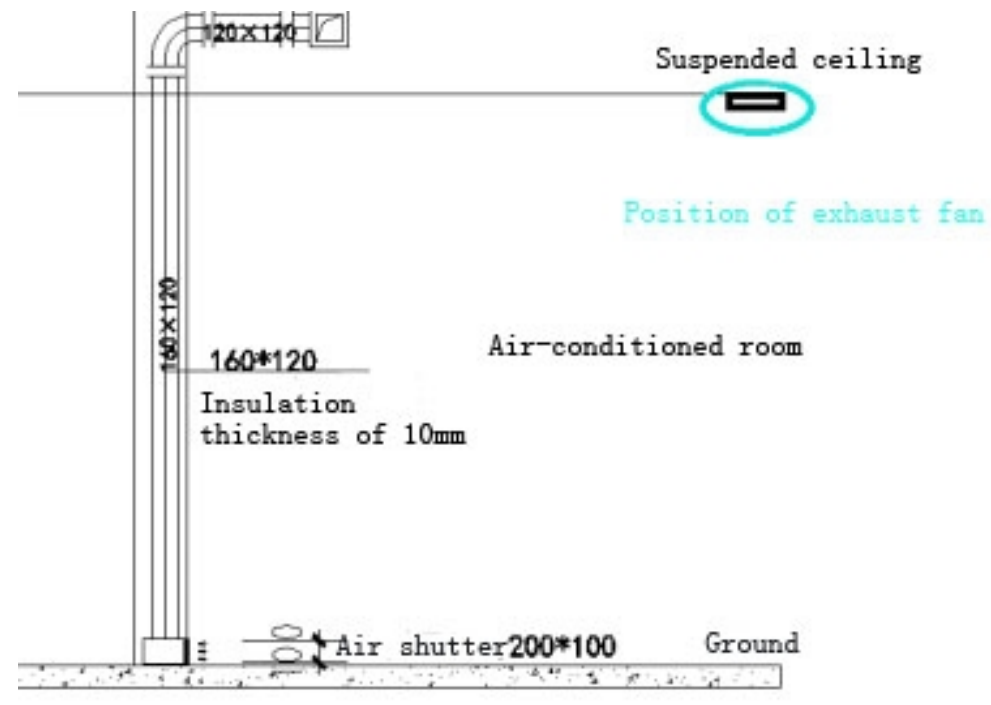

Fig.1 Schematic of blower installation and indoor temperature and humidity test in winter and summer

Data analysis During the test, the temperatures of indoor six regions and outdoor were obtained by temperature sensors. The results of temperatures in a day and in the entire measurement period were given in Table 1, Fig. 2 and Fig. 3 respectively. From the measurements, we could find that the outdoor temperature had a great influence on the indoor temperature. Similarly, the measurements results of humidity were listed in Table 2, Fig.4 and Fig.5. Through comparative analysis, the change trend of temperature and humidity were almost identical. 
Table 1 Change of temperatures in a day

\begin{tabular}{|c|c|c|c|c|c|c|c|}
\hline Time & $\begin{array}{l}\text { Temperatur } \\
\text { e of region } 1 \\
\left({ }^{\circ} \mathrm{C}\right)\end{array}$ & $\begin{array}{l}\text { Temperatur } \\
\text { e of region } 2 \\
(\stackrel{\text { C })}{ }\end{array}$ & $\begin{array}{l}\text { Temperatur } \\
\text { e of region } 3 \\
(\stackrel{\text { oc })}{ }\end{array}$ & $\begin{array}{l}\text { Temperatur } \\
\text { e of region } 4 \\
(\stackrel{\text { oc })}{ }\end{array}$ & $\begin{array}{l}\text { Temperatur } \\
\text { e of region } 5 \\
(\stackrel{\text { C })}{ }\end{array}$ & $\begin{array}{l}\text { Temperatur } \\
\text { e of region } 6 \\
\quad(\stackrel{\mathrm{o}}{ })\end{array}$ & $\begin{array}{c}\text { Outdoor } \\
\text { temperature } \\
(\stackrel{\circ}{ } \text { C })\end{array}$ \\
\hline $0: 00$ & 22.1 & 23.2 & 22.3 & 22.2 & 23.2 & 24.2 & 21.9 \\
\hline 1:00 & 22 & 22.9 & 22.1 & 22 & 22.9 & 24 & 21.7 \\
\hline $2: 00$ & 21.7 & 22.7 & 21.9 & 21.7 & 22.8 & 23.8 & 21.3 \\
\hline $3: 00$ & 21.5 & 22.4 & 21.7 & 21.5 & 22.4 & 23.5 & 21.3 \\
\hline $4: 00$ & 21.3 & 22.2 & 21.4 & 21.2 & 22.3 & 23.4 & 21.2 \\
\hline $5: 00$ & 21 & 22 & 21.3 & 21.1 & 22 & 23.1 & 21.2 \\
\hline $6: 00$ & 20.9 & 21.9 & 21.1 & 20.9 & 21.9 & 23 & 21.2 \\
\hline 7:00 & 20.8 & 21.8 & 20.9 & 20.9 & 21.9 & 23 & 21.1 \\
\hline 8:00 & 20.7 & 21.8 & 20.9 & 20.8 & 21.7 & 22.8 & 20.9 \\
\hline 9:00 & 22 & 23.5 & 24 & 23.3 & 23.5 & 23.6 & 22 \\
\hline 10:00 & 24.3 & 26.5 & 26.7 & 26.4 & 26.4 & 25.9 & 22.6 \\
\hline 11:00 & 25 & 27.2 & 27.7 & 27.1 & 27.1 & 26.6 & 23.2 \\
\hline $12: 00$ & 25.4 & 27.4 & 27.6 & 27.1 & 27.2 & 27 & 23.1 \\
\hline 13:00 & 25.9 & 28.2 & 28.5 & 28 & 28 & 27.6 & 22.7 \\
\hline $14: 00$ & 25.7 & 27.6 & 27.7 & 27.4 & 27.5 & 27.4 & 21.7 \\
\hline $15: 00$ & 26.1 & 28.1 & 28 & 27.8 & 28 & 27.8 & 21.3 \\
\hline $16: 00$ & 26.3 & 28.3 & 28.2 & 28 & 28.2 & 28 & 21 \\
\hline 17:00 & 26.5 & 28.4 & 28.4 & 28.2 & 28.4 & 28.3 & 20.2 \\
\hline 18:00 & 26 & 27.9 & 28 & 27.5 & 27.7 & 27.7 & 19.5 \\
\hline 19:00 & 25.9 & 28 & 27.9 & 27.6 & 28 & 28.1 & 18.9 \\
\hline 20:00 & 24.5 & 25.6 & 25.3 & 24.7 & 25.8 & 26.3 & 18.6 \\
\hline 21:00 & 23.8 & 24.7 & 24.3 & 23.8 & 24.4 & 25.5 & 18.5 \\
\hline 22:00 & 23.3 & 24.2 & 23.9 & 23.4 & 24.1 & 25 & 18.2 \\
\hline 23:00 & 22.8 & 23.9 & 22.7 & 22.8 & 23.3 & 24.8 & 18.4 \\
\hline
\end{tabular}

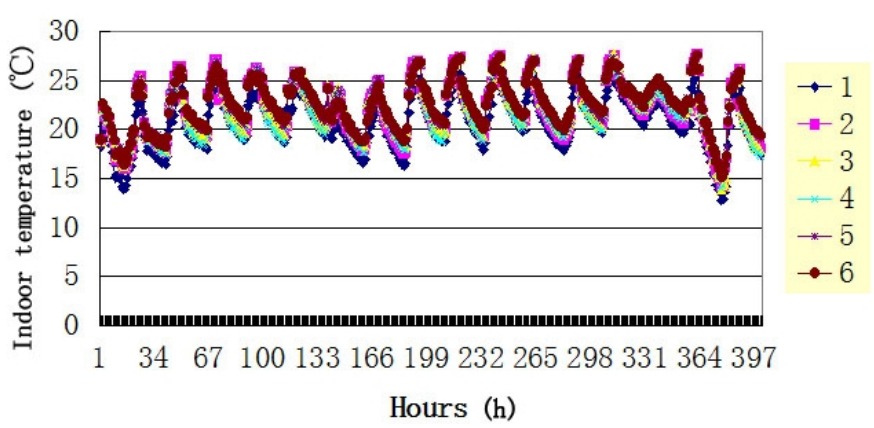

Fig.2 Measurements of indoor temperatures

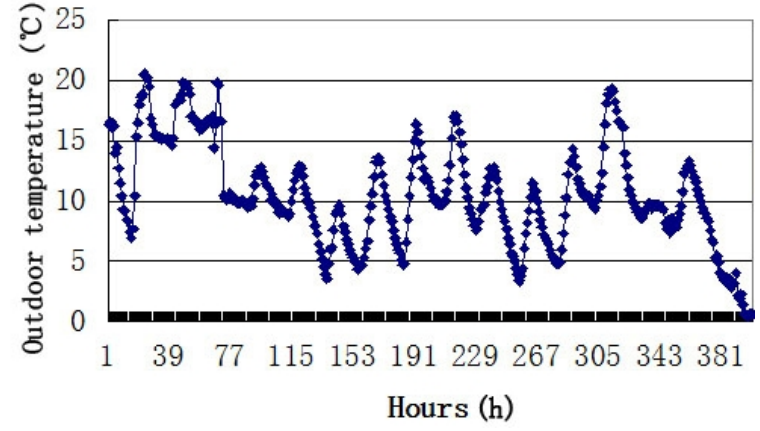

Fig. 3 Measurements of outdoor temperature 
Table 2 Change of humidity in a day

\begin{tabular}{|c|c|c|c|c|c|c|c|}
\hline Time & $\begin{array}{l}\text { Humidity of } \\
\text { region } 1(\%)\end{array}$ & $\begin{array}{l}\text { Humidity of } \\
\text { region } 2(\%)\end{array}$ & $\begin{array}{l}\text { Humidity of } \\
\text { region } 3(\%)\end{array}$ & $\begin{array}{l}\text { Humidity of } \\
\text { region } 4(\%)\end{array}$ & $\begin{array}{l}\text { Humidity of } \\
\text { region } 5(\%)\end{array}$ & $\begin{array}{l}\text { Humidity of } \\
\text { region } 6(\%)\end{array}$ & $\begin{array}{c}\text { Outdoor } \\
\text { humidity }(\%)\end{array}$ \\
\hline $0: 00$ & 25.2 & 24.5 & 24.9 & 24.8 & 23.8 & 22.2 & 27.4 \\
\hline $1: 00$ & 25.6 & 24.9 & 25.6 & 25.2 & 24.2 & 22.7 & 27.8 \\
\hline $2: 00$ & 25.7 & 25 & 25.5 & 25.2 & 24.1 & 22.8 & 27.8 \\
\hline $3: 00$ & 25.7 & 25 & 25.6 & 25.2 & 24.4 & 22.7 & 27.8 \\
\hline 4:00 & 25.9 & 25.1 & 25.7 & 25.5 & 24.5 & 22.8 & 27.9 \\
\hline $5: 00$ & 26.1 & 25.3 & 25.8 & 25.5 & 25.1 & 23 & 27.8 \\
\hline $6: 00$ & 26.4 & 25.5 & 26.1 & 26 & 25.1 & 23.3 & 27.9 \\
\hline 7:00 & 26.5 & 25.8 & 26.4 & 26.3 & 25.1 & 23.4 & 28.1 \\
\hline 8:00 & 26.9 & 26.2 & 26.6 & 26.4 & 25.5 & 23.9 & 28.4 \\
\hline 9:00 & 26.3 & 24.9 & 23.4 & 24 & 24.3 & 23.7 & 28 \\
\hline $10: 00$ & 24.2 & 22 & 20.9 & 20.9 & 21.5 & 22 & 27.9 \\
\hline $11: 00$ & 23.7 & 21.7 & 20.3 & 20.6 & 21.2 & 21.8 & 28.4 \\
\hline $12: 00$ & 23.6 & 21.8 & 20.7 & 21 & 21.2 & 21.6 & 29.2 \\
\hline $13: 00$ & 23.7 & 21.7 & 20.5 & 20.6 & 21.2 & 21.6 & 31 \\
\hline $14: 00$ & 24.5 & 22.8 & 21.8 & 21.7 & 22 & 22.2 & 33.6 \\
\hline $15: 00$ & 23.8 & 22.1 & 21.3 & 21.3 & 21.5 & 21.8 & 34.7 \\
\hline $16: 00$ & 23.7 & 22.1 & 21.4 & 21.1 & 21.5 & 21.6 & 35.1 \\
\hline $17: 00$ & 23.5 & 22 & 21.2 & 21.1 & 21.4 & 21.6 & 36.6 \\
\hline $18: 00$ & 25.5 & 23.8 & 22.9 & 23.1 & 23.2 & 23.5 & 44.4 \\
\hline $19: 00$ & 26.6 & 24.2 & 23.4 & 23.5 & 23.4 & 23.6 & 45.5 \\
\hline 20:00 & 28.2 & 27.3 & 26.8 & 27.2 & 26.1 & 25.8 & 46.1 \\
\hline 21:00 & 29.4 & 28.8 & 28.4 & 28.8 & 28.1 & 26.6 & 45.6 \\
\hline $22: 00$ & 29.9 & 29.4 & 28.8 & 29.2 & 28.5 & 27.2 & 45.7 \\
\hline 23:00 & 30.6 & 29.9 & 30.9 & 30.1 & 29.6 & 27.4 & 43.5 \\
\hline
\end{tabular}

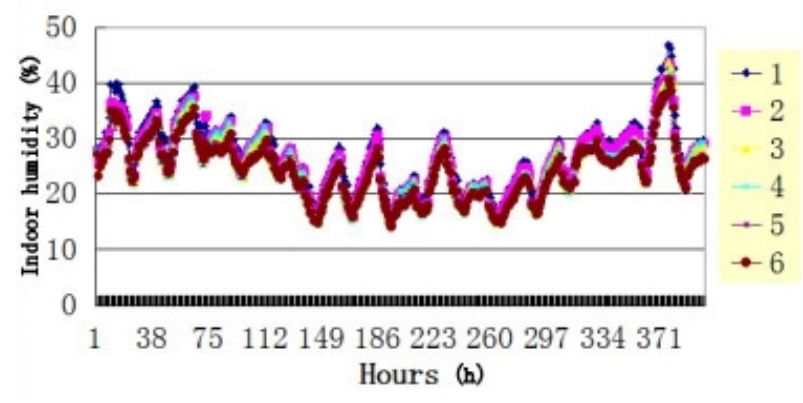

Fig.4 Measurements of indoor humidity

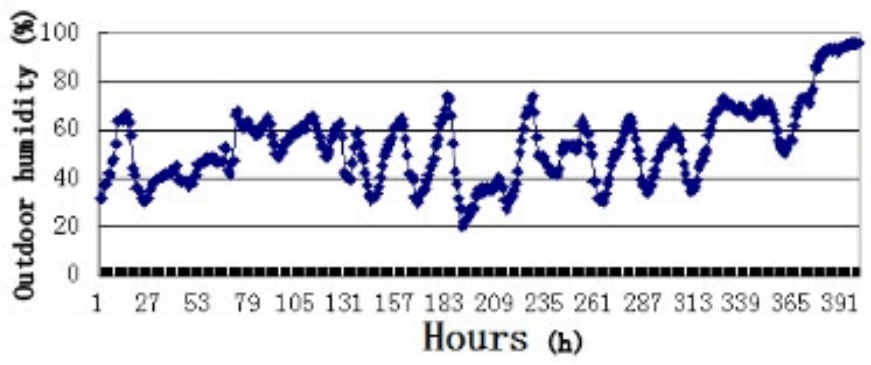

Fig.5 Measurements of outdoor humidity

\section{Finite element simulation of CFD for scheme optimization}

The computational fluid dynamics software of ANSYS was employed to simulate the air flow performance in the testing room. Test room finite element model is shown in Fig. 6. And the setting parameters during simulations are listed in Table 3 . The air velocities and temperature of air were 0.2 $\mathrm{m} / \mathrm{s}, 0.3 \mathrm{~m} / \mathrm{s}, 294.7 \mathrm{~K}$ and $298 \mathrm{~K}$ respectively. Firstly, according to the measured data, the accuracy of finite element model was validated. And then a variety of operating cases were set to optimize the indoor air flow organization scheme. 


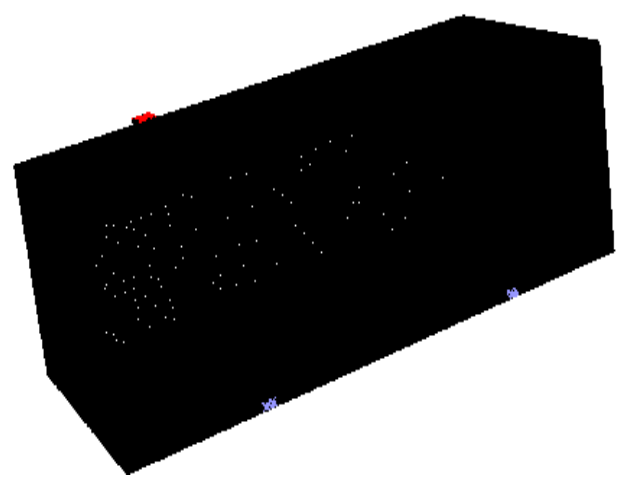

Fig. 6 Test room finite element model

Table 3 Setting parameters of simulations

\begin{tabular}{ccc}
\hline Item & Air velocity $(\mathrm{m} / \mathrm{s})$ & Temperature $(\mathrm{K})$ \\
\hline Case 1 & 0.2 & 294.7 \\
Case 2 & 0.3 & 298 \\
Case 3 & 0.2 & 298 \\
Case 4 & 0.3 & 294.7 \\
\hline
\end{tabular}

The task of air flow organization was organizing the indoor air flow reasonably. The adjusted temperature, humidity and velocity of the indoor air could meet the requirement of health and comfort. Four main factors of affecting the human thermal comfort were the type of air supply inlet, the distance between the body and air supply inlet, the air velocity and temperature. Based on the comfort requirement and the importance of various factors, the indoor air distribution could be optimized. For the different calculation conditions, the numerical simulations were carried out. And the simulation results of temperature and velocity distributions were shown in Figs. 7 - 10.

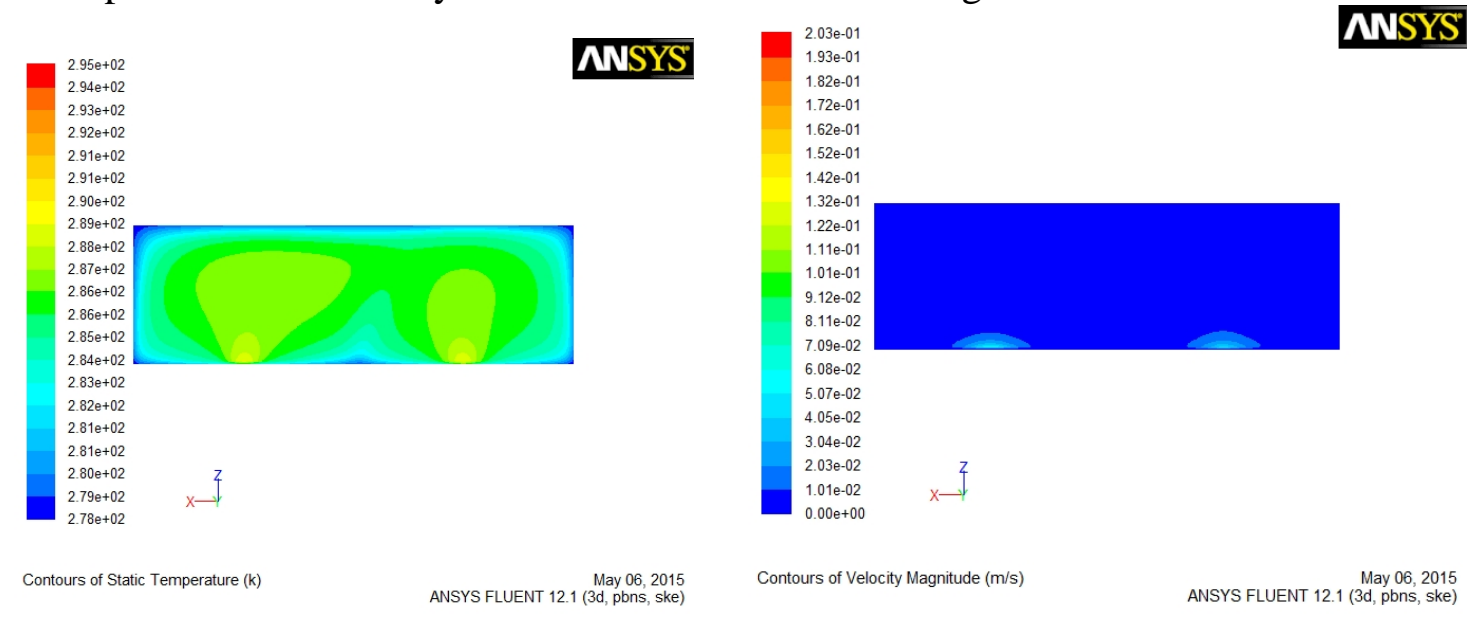

Fig. 7 Simulation results of temperature and velocity distributions under case 1

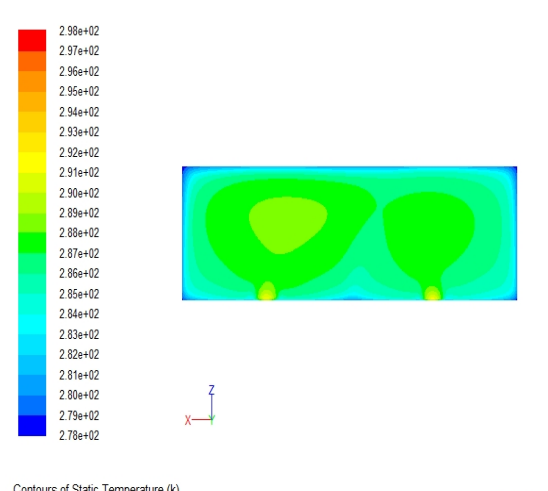

\section{MNSY}

May 00,2015
ANSYS FLUENT 12.1 (3d, pbns, ske)
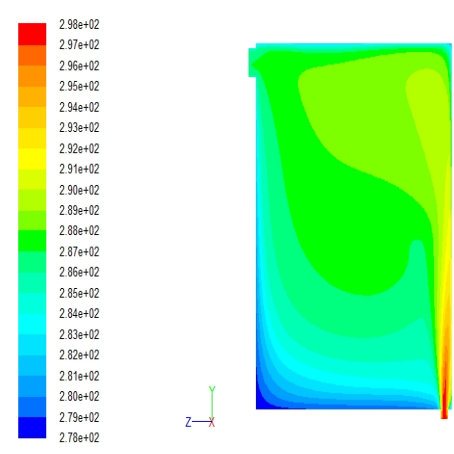

May 06, 2015
ANSYS FLUENT 12. (3d, pbns, ske)

Fig. 8 Simulation results of temperature and velocity distributions under case 2 

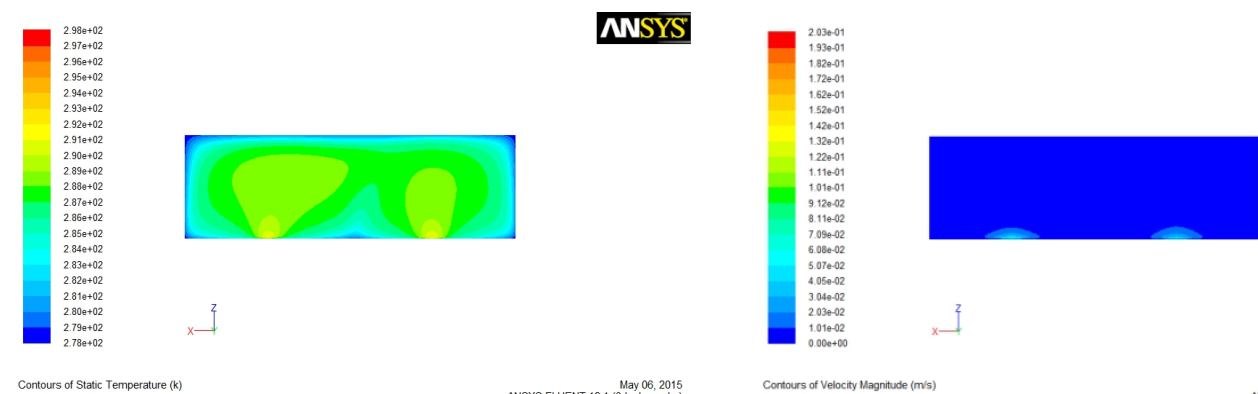

Fig. 9 Simulation results of temperature and velocity distributions under case 3
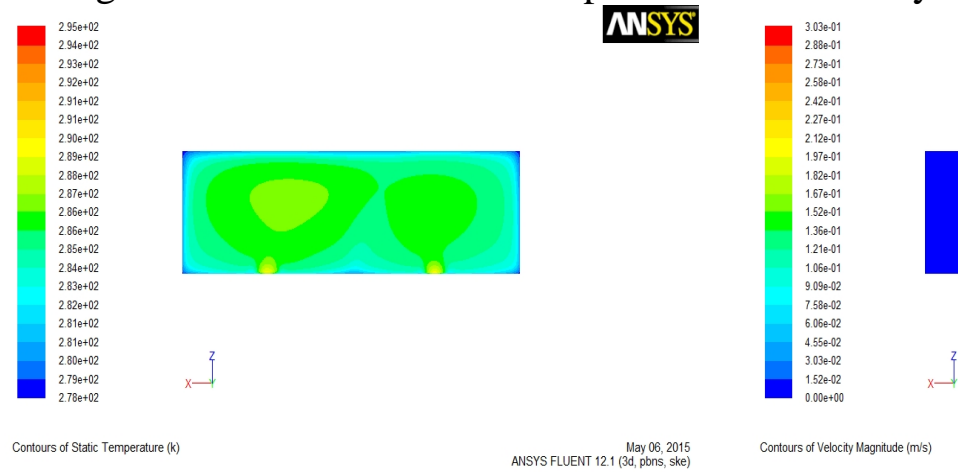

Fig. 10 Simulation results of temperature and velocity distributions under case 4

\section{Results and Discussion}

Through the results of experiment and numerical simulation, the primary and secondary order of four factors that affected the comfort of human body in the indoor air distribution was the distance between the body and air supply inlet, the air temperature, the air velocity and the type of air supply inlet. Due to the factor of the type of air supply inlet with little impact, it could be ignored.

\section{Acknowledgment}

This work was financially supported by the National Nature Science Found of China (No.51606002), the Natural Science Major Research Projects of Anhui Education Department (Grant No. KJ2016SD14), and Science and Technology Major Projects of Anhui province (No. 16030801118).

\section{References}

[1] Li B, Yao R. Urbanization and its impact on building energy consumption and efficiency in China. Renewable Energy, 2009, 34(9):1994-1998.

[2] Yang J, Zhou B, Jin M, et al. A novel complex air supply model for indoor air quality control via the occupant micro-environment demand ventilation. Chaos Solitons \& Fractals, 2016, 89:474-484.

[3] Tao H, Fan Y, Li X, et al. Investigation of formaldehyde and TVOC in underground malls in Xi'an, China: Concentrations, sources, and affecting factors. Building \& Environment, 2015, 85:85-93.

[4] An J Y, Kim S, Kim H J. Formaldehyde and TVOC emission behavior of laminate flooring by structure of laminate flooring and heating condition. Journal of Hazardous Materials, 2011, 187(1-3):44-51.

[5] Chi C, Chen W, Guo M, et al. Law and features of TVOC and formaldehyde pollution in urban indoor air. Atmospheric Environment, 2016, 132:85-90.

[6] Kim S, Kim J A, Kim H J, et al. Determination of formaldehyde and TVOC emission factor from wood-based composites by small chamber method. Polymer Testing, 2006, 25(5): 605-614. 